\title{
Evaluation of the Risk of Spreading Endometrial Cell by Hysteroscopy: A Prospective Longitudinal Study
}

\author{
Rievani de Sousa Damião, ${ }^{1}$ Reginaldo Guedes Coelho Lopes, ${ }^{1}$ Emilly Serapião dos Santos, ${ }^{1}$ \\ Umberto Gazzi Lippi, ${ }^{1}$ and Eduardo Borges da Fonseca ${ }^{1,2}$ \\ ${ }^{1}$ Departamento de Obstetrícia e Ginecologia, Hospital do Servidor Publico Estadual, "Francisco Morato de Oliveira", \\ Rua Pedro de Toledo 1800, 04039-901 São Paulo, SP, Brazil \\ ${ }^{2}$ School of Medicine, University of São Paulo, São Paulo, SP, Brazil
}

Correspondence should be addressed to Rievani de Sousa Damião, rievani@yahoo.com

Received 23 November 2008; Accepted 27 February 2009

Recommended by John J. Sciarra

Objective. The aim was to assess the intraperitoneal spread of endometrial cells during hysteroscopy. Study Design. Seventy-six women were submitted to a hysteroscopy with $\mathrm{CO}_{2}$ under a low pressure. Group 1 had not previous diagnosis of endometrial cancer, and group 2 had previous diagnosis of endometrial cancer (stage I-92.3\%). Two peritoneal washing samples were taken before (PW1) and immediately after (PW2) the procedure. The dissemination for the peritoneal cavity was defined by the presence of endometrial cells in the PW2; such cells should be absent in WP1. Results. Four patients were excluded for presenting endometrial cells in PW1. In the 72 patients left, there was no passage of cells for the peritoneal cavity. In group 1,88\% presented secretory endometrial phase with correlation of $80 \%$ between hysteroscopy and biopsy. Conclusion. Hysteroscopy performed under a low pressure of $\mathrm{CO}_{2}$ does not cause spreading of endometrial cells into the peritoneal cavity.

Copyright (C) 2009 Rievani de Sousa Damião et al. This is an open access article distributed under the Creative Commons Attribution License, which permits unrestricted use, distribution, and reproduction in any medium, provided the original work is properly cited.

\section{Introduction}

Hysteroscopy has been established as the gold standard procedure to evaluate and to treat abnormal uterine bleeding $[1,2]$. The uterine cavity can be thoroughly visualized and an endometrial biopsy specimen can be taken under hysteroscopic view $[3,4]$. An endometrial carcinoma can be detected in $7 \%-10 \%$ of postmenopausal patients and $2 \%$ $3 \%$ of premenopausal patients submitted to hysteroscopy $[5,6]$. In view of these, hysteroscopy is now considered as an important method in the investigation of endometrial cancer [3-6].

Hysteroscopy requires distention of the cavity with a gaseous or liquid medium at a pressure of $50-150 \mathrm{mmHg}$ to allow complete visualization of the fundus and ostial areas. Liquid media used for this purpose include high-viscosity fluids such as $32 \%$ dextran 70 or low-viscosity fluids such as $5 \%$ dextrose, Ringer's or normal saline solution. The gas universally used for diagnostic hysteroscopy is carbon dioxide $\left(\mathrm{CO}_{2}\right)$. There is evidence from observational studies that distension of uterine cavity could be associated with transtubal leakage of endometrial cells and tissue reflux into the peritoneal cavity [7-12] (Table 1).

It has also been demonstrated that liquid distention appears to have a higher leakage of endometrial cells compared to $\mathrm{CO}_{2}$ distention. On the other hand, there are studies, looking at $\mathrm{CO}_{2}$ distention, that presented contradictory results $[7,11,13]$.

In fact, transtubal leakage of endometrial cell during hysteroscopy is of concern when investigating women complaining of abnormal uterine bleeding who are subsequently found to have endometrial malignancy. Several investigators have reported on retrograde seeding of endometrial carcinoma during hysteroscopy [14-16]. However, these results are controversial in view of different pressure and method of distention.

Although the clinical implication of such reflux has not yet been determined, in principle, it would be avoided in high-risk patients. The current evidence suggests that this would be best achieved with gaseous distention rather than 
TABle 1: Studies reporting on the association between hysteroscopy and positive peritoneal cytology where N: number of cases; PW: peritoneal washing.

\begin{tabular}{|c|c|c|c|c|c|}
\hline \multirow{2}{*}{ Author } & \multirow{2}{*}{$N$} & \multirow{2}{*}{$\begin{array}{l}\text { Indication for } \\
\text { surgery }\end{array}$} & \multicolumn{2}{|c|}{ Hysteroscopy } & \multirow{2}{*}{$\begin{array}{l}\text { Laparoscopy } \\
\text { Positive PW }\end{array}$} \\
\hline & & & Distention & Pressure & \\
\hline Ranta et al. [7] & 51 & Infertility & $\mathrm{CO}_{2}$ & $80 \mathrm{mmHg}$ & $8 / 51(15.6 \%)$ \\
\hline Sagawa et al. [8] & 24 & Endometrial cancer & $\begin{array}{l}\text { Glucose solution } \\
\text { or dextran }\end{array}$ & $50 \mathrm{cmH}_{2} \mathrm{O}$ & $2 / 24(8.4 \%)$ \\
\hline Leveque et al. [9] & 19 & Endometrial cancer & $\begin{array}{l}\mathrm{CO}_{2} \mathrm{NaCl} 0.9 \%(2 \\
\text { cases) }\end{array}$ & $150 \mathrm{mmHg}$ & $7 / 19(36.8 \%)$ \\
\hline Gücer et al. [10] & 31 & Endometrial cancer & $\mathrm{NaCl} 0.9 \%$ & $200 \mathrm{mmHg}$ & $3 / 31(9.7 \%)$ \\
\hline Lo et al. [11] & 70 & Endometrial cancer & $\mathrm{CO}_{2}$ & $100 \mathrm{mmHg}$ & $1 / 70(1.4 \%)$ \\
\hline Lo et al. [11] & 50 & Endometrial cancer & $\mathrm{NaCl} 0.9 \%$ & $100 \mathrm{cmH}_{2} \mathrm{O}$ & $7 / 50(14 \%)$ \\
\hline Solima et al. [12] & 40 & $\begin{array}{l}\text { Endometrial cancer } \\
\text { (Stage I or II) }\end{array}$ & $\mathrm{NaCl} 0.9 \%$ & $40 \mathrm{mmHg}$ & $2 / 40(5 \%)$ \\
\hline
\end{tabular}

with liquid distention. To investigate the influence of the uterine distention medium on tubal reflux, we conducted a prospective longitudinal study using hysteroscopy with $\mathrm{CO}_{2}$ at a pressure of $80 \mathrm{mmHg}$ (low-pressure hysteroscopy) to assess the occurrence of eventual leakage of endometrial cells into the peritoneal cavity in women with and without endometrial cancer.

\section{Material and Methods}

Seventy-six patients were initially enrolled; sixty one underwent laparoscopy for tubal sterilization or other indications (group 1), and fifteen required laparotomy due to endometrial cancer (group 2).

The inclusion criteria were normal reproductive function with patent Fallopian tubes and no history of either tubal disease or tubal surgery, over 3 months of oral contraceptive use discontinuation, no history of pregnancy within the last year. The exclusion criteria were peritoneal cytology positive for endometrial cells after first peritoneal washing (PW1) and negative tubal patency test.

The study was carried out in a sequence of two stages. In the initial stage, either laparoscopy (in group 1) or laparotomy (in group 2) was performed, and peritoneal cells were collected for cytology study (control sample) by injecting $40 \mathrm{~mL}$ of normal saline solution (PW1) in the Douglas pouch, around the tubes and ovaries. When laparotomy was performed, a syringe containing $40 \mathrm{~mL}$ of saline solution was used for injection and aspiration of the peritoneal washing. When laparoscopy was performed, a second puncture was performed where a $5 \mathrm{~mm}$ Endopath trocar (Johnson \& Johnson) was used for injection and aspiration of the peritoneal washing.

In the second stage, diagnostic hysteroscopy was performed by a standard hysteroscope with a $30^{\circ}$ forwardoblique lens and $5 \mathrm{~mm}$ diagnostic sheath. An electronic Hamou hysteroflator (Karl Storz GmbH, Tuttingen, Germany), adjusted to a flow rate $\leq 50 \mathrm{~mL} / \mathrm{min}$ and pressure $\leq 80 \mathrm{mmHg}$ of $\mathrm{CO}_{2}$, was used to distend the intrauterine cavity. All hysteroscopies were performed by the same operator and lasted 4 minutes average. A second peritoneal washing (PW2) was performed using the same technique as that in stage one. Tubal patency was confirmed after the second sample was taken by transcervical injection of $20 \mathrm{~mL}$ methylene blue dye dilution through a cervical cannula. A selective endometrial sampling by hysteroscopy was performed immediately before PW2.

The two samples of the peritoneal washing (before hysteroscopy-PW1; after hysteroscopy-PW2) were fixed in $95 \%$ ethyl alcohol and centrifuged at $3000 \mathrm{~g}$ for 10 minutes. After being fixed by Papanicolaou staining technique, the samples were analyzed at $100 \times$ magnification. Cells were assessed morphologically. Endometrial and tubal cells were identified as nonciliated or ciliated epithelial cells, respectively. In addition, the samples were studied in a blind manner with respect to the diagnosis by an experienced cytopathologist.

Positive peritoneal cytology was considered the primary endpoint of this study. Frequency distribution of ordered categorical variables was compared by means of exact Wilcoxon rank-sum test. Correlations between dichotomous variables were tested using Fisher's exact test. The data were analyzed using the chi-square test, and $P$-value of .05 was considered significant. The study was previously approved by the ethical committee.

\section{Results}

From the initial 76 patients, four $(5.2 \%)$ were excluded due to positive peritoneal cytology after PW1. Two of these had endometrial cancer (stage IIIAG2), and two were in secretory phase of menstrual cycle. Therefore, 72 women participated, of which 13 had endometrial cancer (18.0\%), were labeled group 2, and 59 who had no endometrial cancer $(82.0 \%)$ were labeled group 1.

The characteristics of all these patients are presented in Tables 2 and 3. The previous diagnosis of endometrial cancer had been made by hysteroscopy plus biopsy. The interval time between diagnoses of cancer and surgery was 28 (2440) days.

Among patients of group 2, $11(84.6 \%)$ were in the postmenopausal phase and two $(15.4 \%)$ in premenopausal 
TABLE 2: Characteristics of patients with benign endometrial cytology (group 1).

\begin{tabular}{lcc}
\hline & $N$ & $\%$ \\
\hline Numbers of patients & $59 / 72$ & 81.9 \\
Age years (range) & $35(17-41)$ & - \\
Nulliparous & 10 & 17.0 \\
Laparoscopy indication & & \\
$\quad$ Tubal sterilization & 36 & 61.0 \\
$\quad$ Hysterectomy & 14 & 23.7 \\
$\quad$ Ovarian mass & 6 & 10.2 \\
$\quad$ Chronic pelvic pain & 3 & 5.1 \\
Phase of menstrual cycle & & \\
$\quad$ Secretory & 52 & 11.9 \\
$\quad$ Proliferative & 7 & \\
\hline
\end{tabular}

TABLE 3: Characteristics of patients with cancer (group 2); group1: $<5 \%$ of a nonsquamous or nonmorular solid growth pattern; group2: $6-50 \%$ of a nonsquamous or nonmorular solid growth pattern.

\begin{tabular}{lcc}
\hline & $N$ & $\%$ \\
\hline Number of patients & $13 / 72$ & 18.1 \\
Age years (range) & $57(51-79)$ & - \\
Hysteroscopy indication & & \\
$\quad$ Abnormal uterine bleeding & 9 & 69.2 \\
$\quad$ Abnormal thickness & 4 & 30.8 \\
Endometrial & & \\
Stages* & & \\
$\quad$ IA1 & 5 & 38.4 \\
$\quad$ IB2 & 3 & 23.1 \\
IC1 & 3 & 7.7 \\
IC2 & 1 & 7.7 \\
IIIIC2 & 1 & \\
\hline
\end{tabular}

Corpus Cancer Staging according to FIGO Stages—1988 Revision.

phase. Hysteroscopy was indicated for abnormal vaginal bleeding in nine cases $(69.2 \%)$ and for abnormal sonographic endometrial thickness in four cases $(30.8 \%)$. The majority of these patients had been staged as I (92.3\%).

In both groups, there were no endometrial cells in the second sample collected immediately after diagnostic hysteroscopy.

\section{Comment}

The data of this study demonstrate that diagnostic hysteroscopy performed under a low pressure of $\mathrm{CO}_{2}$ does not cause spreading of endometrial cells into the peritoneal cavity for both patients with and without early stage of endometrial cancer.

As hysteroscopy is largely indicated in patients with abnormal uterine bleeding, it becomes relevant to demonstrate whether this procedure is safe when underlying endometrial cancer is suspected. Abnormal endometrial cells reflux into the peritoneal cavity after diagnostic hysteroscopy which has been reported in about $16 \%$ of cases might increase the risk of recurrence $[17,18]$.

There is controversy regarding the potential dissemination of malignant endometrial cells into the peritoneal cavity through the Fallopian tubes during diagnostic hysteroscopy. However, retrospective studies have suggested that diagnostic hysteroscopy does not significantly increase the incidence of positive peritoneal cytology in patients with endometrial cancer $[17,19]$.

Stage and grade of endometrium cancer, intrauterine pressure, and the medium of distension used during the hysteroscopy are thought to be related with the spreading of malignant endometrial cells into the peritoneal cavity $[2,3,5,15,17,20,21]$. Nevertheless, there is no prospective study that could point at any of those factors as having a significant role in the spreading of malignant cells to the abdominal cavity.

Early recurrence of endometrial cancer within one year after surgical treatment has been reported as being caused by hysteroscopy dissemination of malignant cells [14-16]. The most important factor associated with transtubal spreading of endometrial cells during hysteroscopy procedure appears to be the intrauterine pressure used. Baker and Adamson [22] observed spreading of endometrial cell after diagnostic hysteroscopy using high intrauterine pressure, and Bettocchi et al. [23] have suggested that intrauterine pressure of $150 \mathrm{mmHg}$ has a higher risk for cell dissemination. Leveque et al. [9] used intrauterine pressure of $150 \mathrm{mmHg}$ and observed a positive peritoneal cytology in $37 \%$ of the cases. In contrast, positive peritoneal cytology is seen in about $1.0 \%$ when the intrauterine pressure was equal or below $100 \mathrm{mmHg}$ [7, 8, 11, 12]. Baker and Adamson have demonstrated that no spread of endometrial cell occurs at intrauterine pressure equal or below $70 \mathrm{mmHg}$ [22]. The main limitation of these studies was that the peritoneal cytology was not taken at the same time as hysteroscopy or as a previous cytology study before hysteroscopy.

Lo et al. [11] have also demonstrated that using a liquid medium for intrauterine distension has a higher association with positive peritoneal cytology after diagnostic hysteroscopy (14\% versus $1.4 \%$ ). Hence, the risk of spreading cell into the peritoneal cavity is lower when this was done by gaseous medium under a low pressure to distend the uterine cavity $[3,10,14,16,24]$.

In our study, we performed diagnostic hysteroscopy using intrauterine pressure no greater than $80 \mathrm{mmHg}$ and $\mathrm{CO}_{2}$ gas to distend the intrauterine cavity. Also, peritoneal cytology was performed before as well as after hysteroscopy. All included patients in the study had absent endometrial cells in the first washing. None of our cases showed positive peritoneal cytology after hysteroscopy.

In conclusion, diagnostic hysteroscopy using intrauterine pressure no greater than $80 \mathrm{mmHg}$ and $\mathrm{CO}_{2}$ gas to distend the intrauterine cavity appears to be a safe procedure in high-risk patient for endometrial cancer. However, further studies are required to assess endometrial cell spreading after diagnostic hysteroscopy in different stages of endometrial cancer with long followup. 


\section{References}

[1] J. Hamou, J. Salat-Baroux, and R. Henrion, "Hysteroscopie et microcolpohysteroscopie. Encyclopedie MedicoChirurgicale," Gynecologie, vol. 72B, no. 10, pp. 11-14, 1985.

[2] F. Nagele, F. Wieser, A. Deery, R. Hart, and A. Magos, "Endometrial cell dissemination at diagnostic hysteroscopy: a prospective randomized cross-over comparison of normal saline and carbon dioxide uterine distension," Human Reproduction, vol. 14, no. 11, pp. 2739-2742, 1999.

[3] E. Cicinelli, N. Comi, P. Scorcia, D. Petruzzi, and S. Epifani, "Hysteroscopy for diagnosis and treatment of endometrial adenocarcinoma precursors: a review of literature," European Journal of Gynaecological Oncology, vol. 14, no. 5, pp. 425-436, 1993.

[4] D. Salet-Lizee, P. Gadonneix, M. Van Den Akker, and R. Villet, "The reliability of study methods of the endometrium. A comparative study of 178 patients," Journal de Gynecologie Obstetrique et Biologie de la Reproduction, vol. 22, no. 6, pp. 593-599, 1993.

[5] T. J. Clark, D. Voit, J. K. Gupta, C. Hyde, F. Song, and K. S. Khan, "Accuracy of hysteroscopy in the diagnosis of endometrial cancer and hyperplasia: a systematic quantitative review," The Journal of the American Medical Association, vol. 288, no. 13, pp. 1610-1621, 2002.

[6] E. Valli, E. Zupi, D. Marconi, E. Solima, G. Nagar, and C. Romanini, "Outpatient diagnostic hysteroscopy," The Journal of the American Association of Gynecologic Laparoscopists, vol. 5, no. 4, pp. 397-402, 1998.

[7] H. Ranta, R. Aine, H. Oksanen, and P. K. Heinonen, "Dissemination of endometrial cells during carbon dioxide hysteroscopy and chromotubation among infertile patients," Fertility and Sterility, vol. 53, no. 4, pp. 751-753, 1990.

[8] T. Sagawa, H. Yamada, N. Sakuragi, and S. Fujimoto, "A comparison between the preoperative and operative findings of peritoneal cytology in patients with endometrial cancer," Asia-Oceania Journal of Obstetrics and Gynaecology, vol. 20, no. 1, pp. 39-47, 1994.

[9] J. Leveque, F. Goyat, J. Dugast, L. Loeillet, J. Y. Grall, and S. Le Bars, "Value of peritoneal cytology after hysteroscopy in endometrial adenocarcinoma stage I," Contraception, Fertilite, Sexualite, vol. 26, no. 12, pp. 865-868, 1998.

[10] F. Gücer, K. Tamussino, O. Reich, F. Moser, G. Arikan, and R. Winter, "Two-year follow-up of patients with endometrial carcinoma after preoperative fluid hysteroscopy," International Journal of Gynecological Cancer, vol. 8, no. 6, pp. 476-480, 1998.

[11] K. W. K. Lo, T. H. Cheung, S. F. Yim, and T. K. H. Chung, "Hysteroscopic dissemination of endometrial carcinoma using carbon dioxide and normal saline: a retrospective study," Gynecologic Oncology, vol. 84, no. 3, pp. 394-398, 2002.

[12] E. Solima, V. Brusati, A. Ditto, et al., "Hysteroscopy in endometrial cancer: new methods to evaluate transtubal leakage of saline distension medium," American Journal of Obstetrics and Gynecology, vol. 198, no. 2, pp. 214.e1-214.e4, 2008.

[13] Y. Beyth, H. Yaffe, T. Reinhartz, and E. Sadovsky, "Peritoneal cavity cytology after uterotubal CO2 insufflation," Fertility and Sterility, vol. 27, no. 7, p. 871, 1976.

[14] S. Romano, Y. Shimoni, D. Muralee, and E. Shalev, "Retrograde seeding of endometrial carcinoma during hysteroscopy," Gynecologic Oncology, vol. 44, no. 1, pp. 116-118, 1992.
[15] M. J. Schmitz and W. A. Nahhas, "Hysteroscopy may transport malignant cells into the peritoneal cavity. Case report," European Journal of Gynaecological Oncology, vol. 15, no. 2, pp. 121-124, 1994.

[16] C. Egarter, C. Krestan, and C. Kurz, "Abdominal dissemination of malignant cells with hysteroscopy," Gynecologic Oncology, vol. 63, no. 1, pp. 143-144, 1996.

[17] C. Yazbeck, C. Dhainaut, A. Batallan, J.-L. Benifla, A. Thoury, and P. Madelenat, "Diagnostic hysteroscopy and risk of peritoneal dissemination of tumor cells," Gynecologie Obstetrique Fertilite, vol. 33, no. 4, pp. 247-252, 2005.

[18] D. Bartosik, S. L. Jacobs, and L. J. Kelly, "Endometrial tissue in peritoneal fluid," Fertility and Sterility, vol. 46, no. 5, pp. 796800, 1986.

[19] O. Tanizawa, A. Miyake, and O. Sugimoto, "Re-evaluation of hysteroscopy in the diagnosis of uterine endometrial cancer," Nippon Sanka Fujinka Gakkai Zasshi, vol. 43, no. 6, pp. 622$626,1991$.

[20] N. Vecek, T. Marinovic, J. Ivic, et al., "Prognostic impact of peritoneal cytology in patients with endometrial carcinoma," European Journal of Gynaecological Oncology, vol. 14, no. 5, pp. 380-385, 1993.

[21] N. Kadar, H. D. Homesley, and J. H. Malfetano, "Prognostic factors in surgical stage III and IV carcinoma of the endometrium," Obstetrics and Gynecology, vol. 84, no. 6, pp. 983-986, 1994.

[22] V. L. Baker and G. D. Adamson, "Threshold intrauterine perfusion pressures for intraperitoneal spill during hydrotubation and correlation with tubal adhesive disease," Fertility and Sterility, vol. 64, no. 6, pp. 1066-1069, 1995.

[23] S. Bettocchi, G. Di Vagno, G. Cormio, and L. Selvaggi, "Intraabdominal spread of malignant cells following hysteroscopy," Gynecologic Oncology, vol. 66, no. 1, pp. 165-166, 1997.

[24] P. G. Rose, G. Mendelsohn, and I. Kornbluth, "Hysteroscopic dissemination of endometrial carcinoma," Gynecologic Oncology, vol. 71, no. 1, pp. 145-146, 1998. 


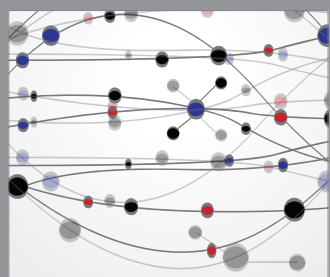

The Scientific World Journal
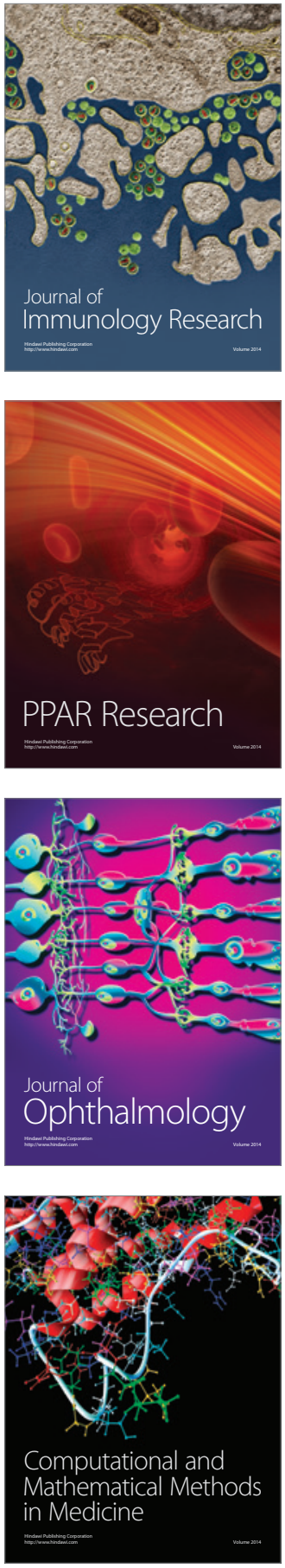

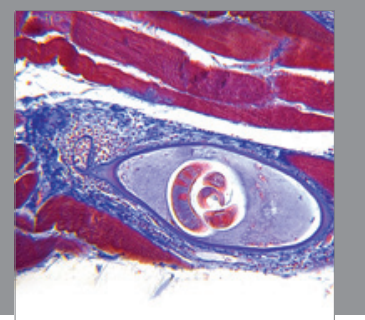

Gastroenterology

Research and Practice
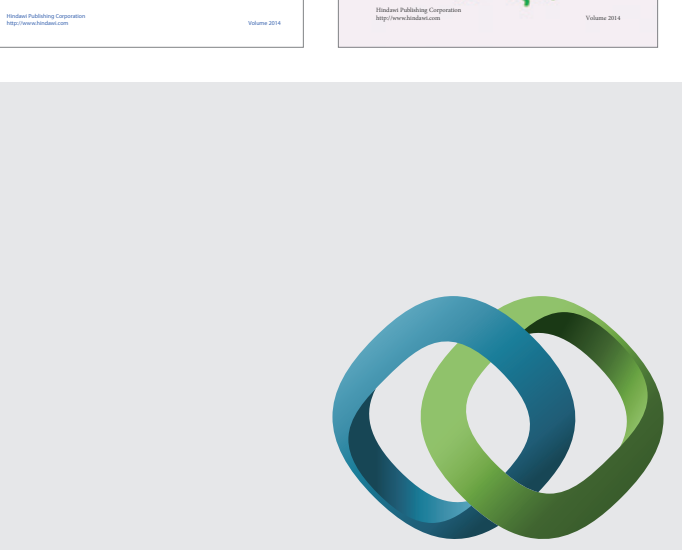

\section{Hindawi}

Submit your manuscripts at

http://www.hindawi.com
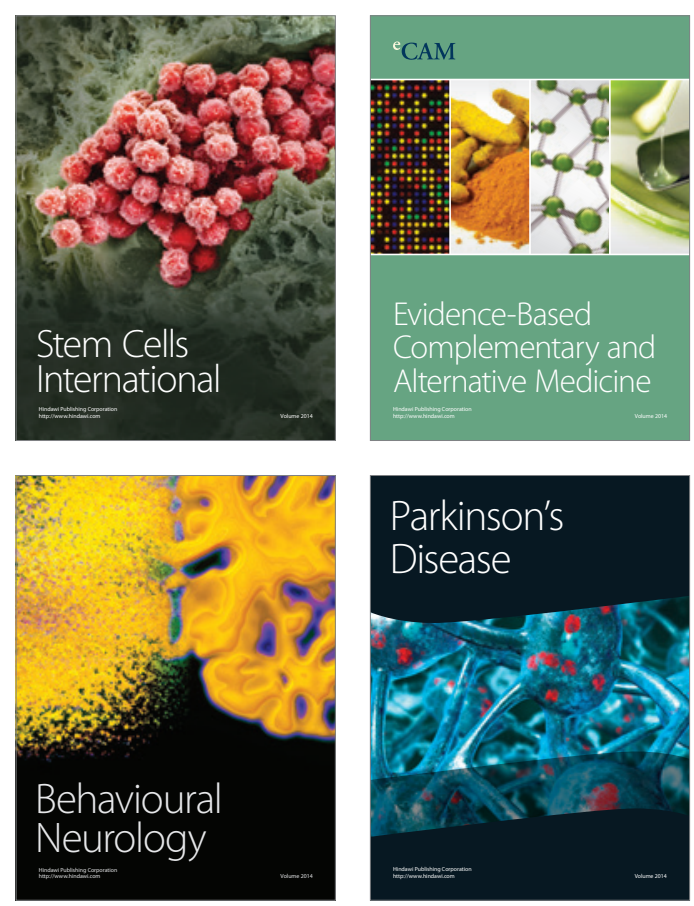

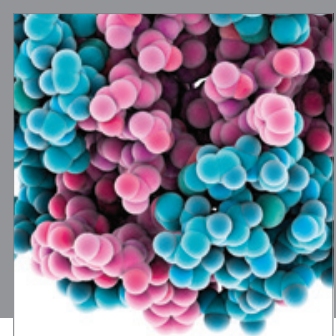

Journal of
Diabetes Research

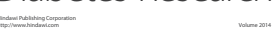

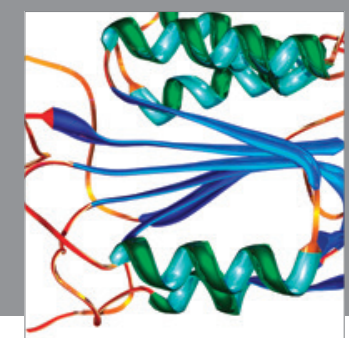

Disease Markers
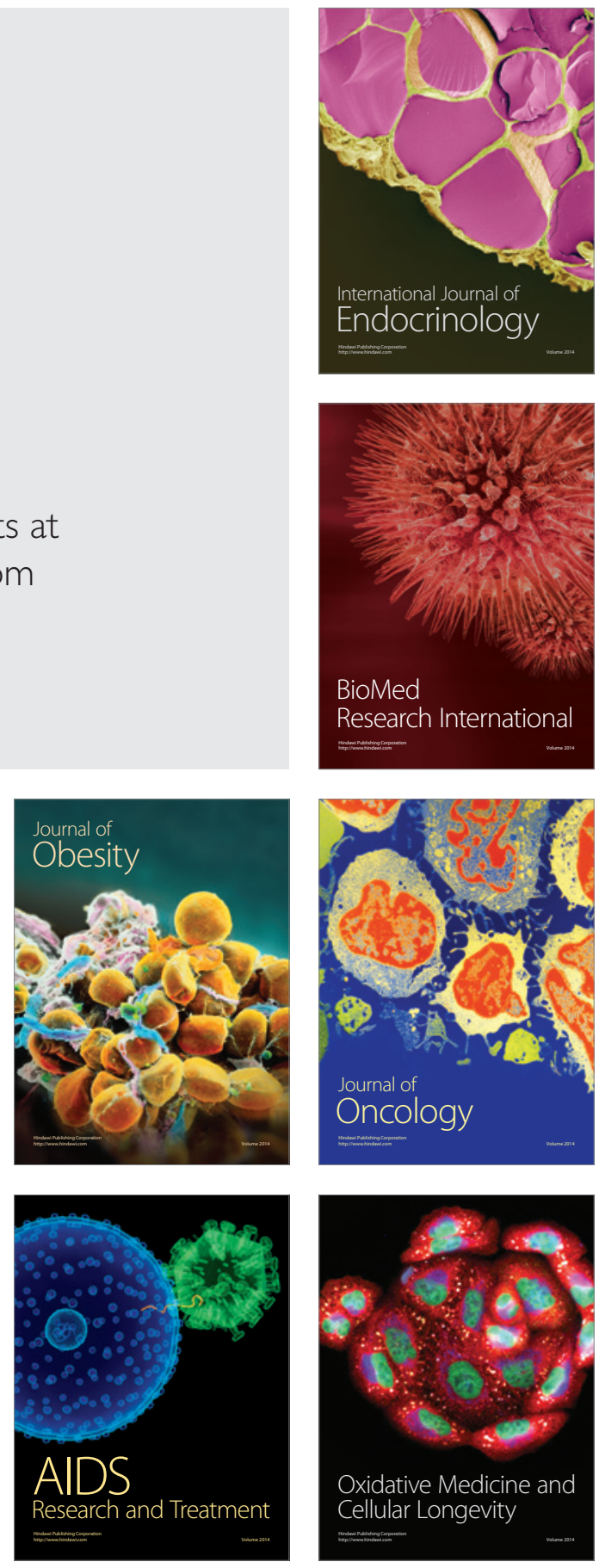